\title{
Immunoglobulin Prevents Complement-mediated Hyperacute Rejection in Swine-to-Primate Xenotransplantation
}

\author{
John C. Magee, ${ }^{*}$ Bradley H. Collins, ${ }^{*}$ Robert C. Harland, * Bonnie J. Lindman, ${ }^{\star}$ R. Randal Bollinger, ${ }^{\star \S}$ Michael M. Frank, \\ and Jeffrey L. Platt**\$ \\ Department of $*$ Surgery, ${ }^{\ddagger}$ Pediatrics, and ${ }^{\S}$ Immunology, Duke University Medical Center, Durham, North Carolina 27710
}

\begin{abstract}
Immunoglobulins regulate the complement system by activating complement on foreign surfaces and diverting reactive complement proteins away from autologous cell surfaces. Based on this model, we explored the ability of Ig to balance complement activation versus control in a pig-toprimate cardiac xenotransplantation model in which the binding of xenoreactive antibodies of the recipient to graft blood vessels and the activation of complement cause hyperacute rejection. Human IgG added to human serum caused a dose-dependent decrease in deposition of iC3b, cytotoxicity, and heparan sulfate release when the serum was incubated with porcine endothelial cells. This decrease was not caused by alteration in antibody binding or consumption of complement but presumably reflected decreased formation of $\mathrm{C} 3$ convertase on the endothelial cells. Infusion of purified human IgG into nonhuman primates prevented hyperacute rejection of porcine hearts transplanted into the primates. As expected, the transplants contained deposits of recipient Ig and C1q but not other complement components. The inhibition of complement on endothelial cell surfaces and in the xenotransplantation model supports the idea that IgG regulates the classical complement pathway and supports therapeutic use of that agent in humoral-mediated disease. (J. Clin. Invest. 1995. 96:2404-2412.) Key words: xenotransplantation - immunoglobulin • gammaglobulin • complement $\cdot$ hyperacute rejection
\end{abstract}

\section{Introduction}

IgG regulates the functions of complement through a number mechanisms. After specific binding to target antigens, IgG interacts with $\mathrm{Clq}$ to initiate the classical complement pathway (1, 2). IgG activates the alternative complement pathway in part by generating $\mathrm{C} 3 \mathrm{~b}$ through classical pathway activation and in part by masking cell surface polyanionic sites which otherwise would promote interaction of factor $\mathrm{H}$ with $\mathrm{C} 3 \mathrm{~b}(3,4)$. IgG also serves as a ligand for covalent attachment of $\mathrm{C} 3 \mathrm{~b}$, protecting $\mathrm{C} 3 \mathrm{~b}$ from inhibition by factor $\mathrm{H}(5,6)$, promoting alter-

Address correspondence to Jeffrey L. Platt, Box 3658, Department of Surgery, Duke University Medical Center, Durham, NC 27710. Phone: 919-681-3857; FAX: 919-681-7263.

Received for publication 23 January 1995 and accepted in revised form 5 July 1995.

J. Clin. Invest.

(C) The American Society for Clinical Investigation, Inc.

0021-9738/95/11/2404/09 \$2.00

Volume 96, November 1995, 2404-2412 native pathway function. In contrast to these properties, IgG may inhibit the action of complement on potential targets. This is in part accomplished by competing with target cells for binding of $\mathrm{C} 3 \mathrm{~b}$, and possibly $\mathrm{C} 4 \mathrm{~b}$, diverting $\mathrm{C} 3$ convertase (s) from antibody-coated target cells (7). For example, we have shown that injection of large amounts of purified Ig prevents complement-mediated vascular collapse and death caused by administration of antibodies against the Forssman antigen in guinea pigs $(7,8)$.

To understand better the balance between the effector and regulatory functions of IgG, we evaluated the extent to which IgG could modify hyperacute xenograft rejection, a well-characterized immune reaction, in which the binding to a graft of xenoreactive natural antibodies (9-12) triggers activation of complement through the classical pathway $(11,13)$ leading to endothelial injury and destruction of the organ graft in minutes to a few hours (14-18). Approximately $1 \%$ of human IgG is thought to consist of natural antibodies directed against Gal $\alpha$ (1-3) Gal $(19,20)$, an epitope expressed by nonprimates (21). Binding of xenoreactive IgM to this structure accounts for up to $80 \%$ of the binding of IgM to porcine endothelial cells and a corresponding fraction of complement activation (22-24). Binding of IgG to this structure is also postulated to contribute to xenograft rejection (25), although the mechanism is uncertain. The administration of human IgG containing these antibodies might thus amplify the immune reaction responsible for rejection of a xenograft or it might lessen or prevent the reaction.

Here we report that while human IgG administered to nonhuman primates does bind to a porcine organ, antibody binding does not lead to an appreciable increase in complement activation on graft blood vessels nor does it alter binding of xenoreactive IgM. Rather, the administration of IgG inhibits deposition of complement via the classical complement pathway on endothelial cells, in most cases preventing complement-mediated hyperacute rejection.

\section{Methods}

Human IgG. Gamimune ${ }^{\circledR}$ N (5\% and 10\%; Miles Laboratories Inc., Elkhart, IN) which was used in most experiments, consists of $98 \%$ IgG (manufacturer's insert). The vehicle for 5\% Gamimune ${ }^{\circledR} \mathrm{N}$ is $9-11 \%$ maltose, the vehicle for $10 \%$ Gamimune ${ }^{\circledR} \mathrm{N}$ is $0.16-0.24 \mathrm{M}$ glycine. Also evaluated were Gammagard ${ }^{\circledR}$ (Baxter Healthcare Corp., Glendale, CA), Gammar ${ }^{\circledR}$ IV (Armour Pharmaceutical Co., Kankakee, IL), and Venoglobulin ${ }^{\circledR}-S$ (Alpha Therapeutic Corp., Los Angeles, CA), which contain predominantly IgG and only trace amounts of IgM and IgA. We therefore refer to the preparations as IgG.

To control for potential effects of the carrier, the IgG preparations were dialyzed against PBS in some experiments. The IgG preparations were then filtered through a $0.22-\mu \mathrm{m}$ filter (Costar Scientific Corp., Cambridge, MA), and stored at $4^{\circ} \mathrm{C}$. Immediately before use the solu- 
tions were centrifuged at $100,000 \mathrm{~g}$ for $30 \mathrm{~min}$ to remove Ig aggregates, and the concentration was determined spectrophotometrically. BSA (Fraction V; Sigma Chemical Co., St. Louis, MO) dissolved in PBS at a concentration of $50 \mathrm{mg} / \mathrm{ml}$ and filtered through a $0.22-\mu \mathrm{m}$ filter was used as a control. Immediately before use in vitro, the BSA was centrifuged at $100,000 \mathrm{~g}$ for $30 \mathrm{~min}$ and diluted to the desired concentration.

Human serum. Samples of serum were obtained from healthy human volunteers and stored at $-70^{\circ} \mathrm{C}$. Levels of IgG and IgM were determined by nephelometry. The level of xenoreactive natural antibodies was determined as described below. Serum from a donor with extremely low levels of xenoreactive antibodies was used as a source of human complement $(15,26)$. Incubation of this serum $(25 \% \mathrm{vol} / \mathrm{vol})$ with porcine aortic endothelial cells for $60 \mathrm{~min}$ does not lead to deposition of iC $3 \mathrm{~b}$ as ascertained by ELISA.

Endothelial cell cultures. Porcine aortic endothelial cells were explanted and cultured according to the method of Ryan and Maxwell (27). Cultured in DME containing 10\% FCS, $4 \mathrm{mM} \mathrm{L-glutamine,} 1 \%$ Pen-Strep (Gibco Laboratories, Grand Island, NY), the porcine aortic endothelial cells exhibited cobblestone morphology and endocytosed acetylated LDL. Porcine aortic endothelial cells were grown to confluence (6-11 d) on gelatin-coated $75-\mathrm{cm}^{2}$ flasks (Costar) and passaged 1:3-1:4 by trypsinization. Cells were used between the fourth and twelfth passages.

Immunochemical reagents. Immunopathology was performed using reagents against human proteins which cross-react with primate proteins. Affinity-isolated, FITC-conjugated goat anti-human IgM and affinityisolated, FITC-conjugated goat anti-human IgG were obtained from Sigma Chemical Co. for detection of human antibodies and from Kirkegaard \& Perry (Gaithersburg, MD) for detection of non-human primate antibodies. Affinity-isolated FITC-conjugated goat anti-human C4 and FITC-conjugated rabbit anti-human fibrinogen were from Accurate Chemical and Science Corp. (Westbury, NY). Affinity-isolated FITCconjugated goat anti-human C3 was obtained from Cappel-Organon Teknika (Durham, NC). Murine mAbs against human Clq, iC3b neoantigen, and C5b neoantigen were from Quidel (San Diego, CA). Murine mAbs against a neoantigen of the membrane attack complex (MBM5) was the generous gift of Dr. Alfred F. Michael (University of Minnesota, Minneapolis, MN) (28). Murine monoclonal anti-human CD9 (BA2 ) was the generous gift of T. W. LeBien (University of Minnesota, Minneapolis, MN). FITC-conjugated rabbit anti-human properdin was obtained from Atlantic Antibodies (Stillwater, MN). Goat anti-human factor B was from Calbiochem Corp. (San Diego, CA). Mouse antihuman CD11/CD18 (OKM1) was obtained from Ortho Diagnostic Systems, Inc. (Raritan, NJ).

Measurement of xenoreactive natural antibodies and complement function. Human natural antibodies were measured by ELISA using cultured porcine endothelial cells as a target as previously described (29). Endothelial cells cultured to confluence in 96-well microtiter plates were washed with PBS, fixed with $0.1 \%$ glutaraldehyde for 5 min at $4^{\circ} \mathrm{C}$, washed again with PBS, and then blocked with $1 \%$ BSA. The cells were then incubated with varying concentrations of the human IgG preparation or human serum diluted in PBS for $1 \mathrm{~h}$ at $37^{\circ} \mathrm{C}$. Binding of antibodies to the endothelial cells was detected using alkaline phosphatase-conjugated goat anti-human IgM or alkaline phosphataseconjugated goat anti-human IgG and $p$-nitrophenylphosphate in diethanolamine (Sigma Chemical Co.) as substrate. The reaction product determined by measuring absorbance at $405 \mathrm{~nm}$ with an ELISA plate reader (Bio-Tek Instruments, Inc., Winooski, VT). The ability of xenoreactive antibodies to activate complement was ascertained by exposing porcine endothelial cells to a source of antibody and then to $25 \%$ human complement, for $60 \mathrm{~min}$ at $37^{\circ} \mathrm{C}$. The cells were then again washed, fixed, blocked as described above, and complement activation was determined by measuring the deposition of iC3b by ELISA (26). Binding of $\mathrm{C} 4$ was determined using rabbit anti-human $\mathrm{C} 4$ antibodies (Accurate Antibodies), followed by an alkaline phosphatase-conjugated, mouse monoclonal anti-rabbit Ig (Sigma Chemical Co.). Under the conditions studied, the binding of each complement component studied was linear for a constant concentration of human IgG.

Effect of human IgG on IgM and complement binding to porcine endothelial cells. The effect of human IgG on the binding of IgM and complement to porcine endothelial cells was evaluated by generating binding curves for each concentration of human Ig used. To study the effect of human IgG on binding of xenoreactive IgM, $0-20 \mathrm{mg} / \mathrm{ml}$ of human IgG was added to heat-inactivated human serum for $90 \mathrm{~min}$ at $37^{\circ} \mathrm{C}$. The binding of IgM in the serum to porcine endothelial cells was then measured by ELISA as described above. To study the effect of human IgG on complement activation in this system, porcine endothelial cells were incubated with various concentrations of heat-inactivated human serum for $90 \mathrm{~min}$ at $37^{\circ} \mathrm{C}$ and then with $25 \%$ human complement containing $0-20 \mathrm{mg} / \mathrm{ml} \mathrm{IgG}$ for $90 \mathrm{~min}$ at $37^{\circ} \mathrm{C}$. The binding of complement components to the cell surface was then determined by ELISA as described above.

Endothelial cell cytotoxicity. Cytotoxicity was determined using a standard ${ }^{51} \mathrm{Cr}$ release assay (14). Porcine aortic endothelial cells grown to confluence on 24-well plates were labeled with $2 \mu \mathrm{Ci}$ of $\mathrm{Na}^{51} \mathrm{CrO}_{4}$ (New England Nuclear, Boston, MA) per well for $18 \mathrm{~h}$. The cells were then treated for $4 \mathrm{~h}$ using the experimental or control conditions as indicated. The percentage of cytotoxicity was calculated using the following formula: \% cytotoxicity $=[(A-C) /(A+B-C)] \times 100$ where $A$ equals radioactivity in the supernatant, $B$ equals total radioactivity (extracted with $1.0 \mathrm{~N} \mathrm{NaOH}$ ), and $\mathrm{C}$ equals radioactivity in supernatant of cells treated with heat-inactivated serum.

Heparan sulfate release from endothelial cells. The effects of complement on the metabolism of endothelial cell-associated heparan sulfate proteoglycan was determined as described previously (14). Glycosaminoglycans in endothelial cells cultured as described above were biosynthetically labeled for $16-20 \mathrm{~h}$ in sulfate-free medium containing $1 \% \mathrm{FBS}$ and $0.1 \mathrm{mCi} / \mathrm{ml}\left[{ }^{35} \mathrm{~S}^{2} \mathrm{NaSO}_{4}(14,30)\right.$. In this system, $\sim 96 \%$ of the labeled proteoglycans are heparan sulfate based on sensitivity to deaminative cleavage with nitrous acid.

The monolayers were incubated with $25 \%$ human serum with 0-20 $\mathrm{mg} / \mathrm{ml}$ of IgG for $2 \mathrm{~h}$ and controls with $25 \%$ heat-inactivated serum. The supernatant and cell layers were extracted and dialyzed as previously described (14), and the radioactivity of each fraction was determined by liquid scintillation counting. The percent heparan sulfate release was calculated as follows: $[(\mathrm{cpm}$ medium $) /(\mathrm{cpm}$ medium $+\mathrm{cpm}$ cells $)]$ $\times 100$.

Animals. Outbred, 6-12-kg pigs were used as cardiac xenograft donors (Walnut Hill Farm, Hillsborough, NC, and DNX Inc., Princeton, $\mathrm{NJ}$ ). Male cynomolgus monkeys (Maccaca fascicularis, Crab-eating Macaques), $\sim 8-12 \mathrm{~kg}$ in size and female baboons (Papio species), $14-16 \mathrm{~kg}$, were used as cardiac xenograft recipients.

Harvesting of porcine organs. Pigs were sedated with ketamine hydrochloride and anesthetized with isoflurane, and the kidneys and heart harvested as described previously (31). A cannula was placed in the infrarenal aorta and the suprarenal aorta and vena were then ligated and the kidneys perfused with University of Wisconsin solution (Viaspan; DuPont-Merck Pharmaceutical Co., Wilmington, DE) at $4^{\circ} \mathrm{C}$.

For harvesting of the heart, the superior and inferior vena cava were ligated, the aorta cross-clamped, and the heart brought into arrest by perfusion with cardioplegia solution (Plegisol; Abbott Laboratories Diagnostic Div. Chicago, IL) at $4^{\circ} \mathrm{C}$. The inferior vena cava and right inferior pulmonary vein were incised to vent the heart while saline slush was applied to provide topical cooling.

Porcine to primate cardiac xenografts. Porcine hearts were transplanted into cynomolgus monkeys as previously described (32). On the day before transplantation, human Ig $2 \mathrm{~g} / \mathrm{kg}$ was administered to the monkeys through a dual lumen Hickman catheter (Bard Access Systems, Salt Lake City, UT) placed in the right internal jugular vein. On the day of transplantation, a splenectomy was performed. The donor aorta was anastomosed end to side to the recipient abdominal aorta and the donor pulmonary artery was anastomosed to the inferior vena cava. This created a vascularized, beating, nonworking heart model. Upon 

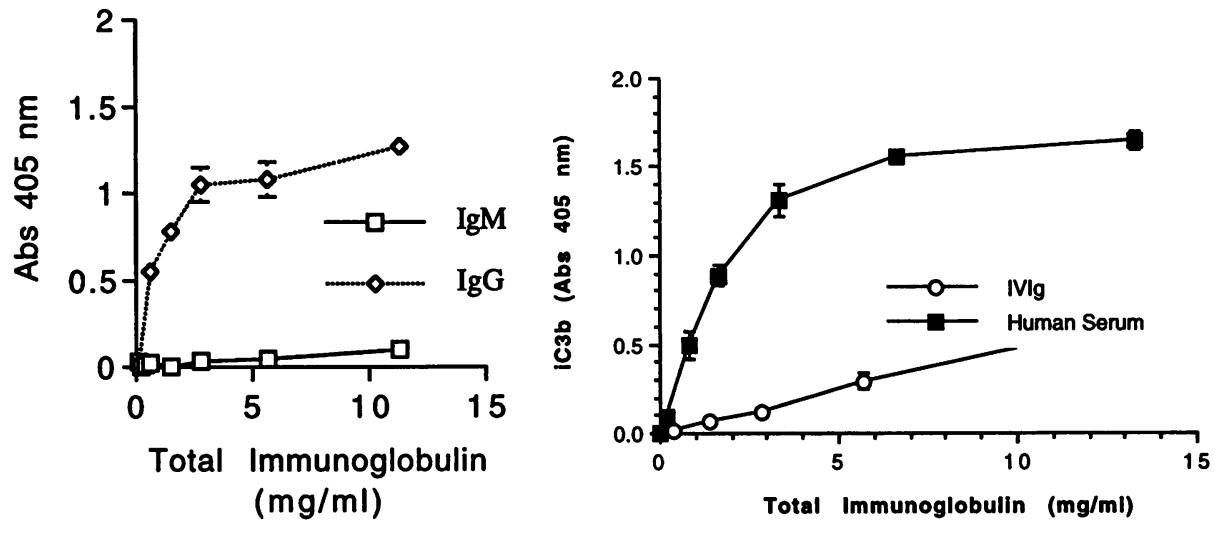

Figure 1. Binding of IgG and IgM in human serum and in purified human IgG to porcine aortic endothelial cells and complement activation. ( $A$ ) Antibody binding. Pig aortic endothelial cells were incubated with various concentrations of purified human $\mathrm{IgG}$ and the binding of $\mathrm{IgG}$ and IgM were determined by ELISA. $A b s$, absorbance. $(B)$ Ability of purified human IgG and of the antibodies in human serum to initiate complement activation on porcine endothelial cells. Porcine aortic endothelial cells were incubated with various concentrations of purified human IgG (IVIg) or heat-inactivated human serum as a source of natural xenoreactive Ig and then with a source of human complement. Generation of iC3b was measured by ELISA. $A b s$, absorbance; IVIg, intravenous Ig. revascularization the heart was defibrillated with 10 joules and resumed sinus rhythm. Total graft preservation time was 70-90 min in most cases. A transmyocardial biopsy was obtained $30-60 \mathrm{~min}$ and $24 \mathrm{~h}$ and after reperfusion of the heart and every $72 \mathrm{~h}$ thereafter.

The recipients were treated with a single dose of heparin $(100 \mathrm{U} /$ $\mathrm{kg}$ ) and immunosuppression consisting of cyclosporine $5-15 \mathrm{mg} / \mathrm{kg}$ per $\mathrm{d}$ adjusted to maintain a blood level of $300 \mathrm{ng} / \mathrm{ml}$, azathioprine, 2 $\mathrm{mg} / \mathrm{kg}$ per $\mathrm{d}$, and methylprednisolone, $8 \mathrm{mg} / \mathrm{kg}$ per $\mathrm{d}$ on the day of transplant tapering over $7 \mathrm{~d}$ to a maintenance dose of $1 \mathrm{mg} / \mathrm{kg}$ per $\mathrm{d}$. Human IgG ( $2 \mathrm{~g} / \mathrm{kg})$ was infused 6-18 h after transplantation and then every $3 \mathrm{~d}$ while the graft continued to function. Graft function was determined by palpation and rejection was defined as cessation of ventricular contractions.

Cardiac xenografts were performed in baboons as previously described (33). In baboon recipients, the preoperative human IgG dose was $3 \mathrm{~g} / \mathrm{kg}$. On the day of transplantation, a splenectomy was performed. Anastomosis of the donor aorta to the carotid artery and donor pulmonary artery to the internal jugular vein were performed as previously described (34-36). Postoperative immunosuppression and biopsy was the same as described for cynomolgus recipients. Graft function was monitored by inspecting the neck for cardiac contraction. In an effort to further extend xenograft survival, the blood of one baboon was perfused through two porcine kidneys as previously described (37).

Histology and immunopathology. Biopsies of the porcine kidneys and hearts were prepared for light and immunofluorescence microscopy as previously described (11). Samples of each biopsy fixed in $10 \%$ formalin were embedded, sectioned, and stained with hematoxylin and eosin. Samples for immunofluorescence studies were snap frozen in precooled isopentane and stored at $-80^{\circ} \mathrm{C}$ until used. Frozen tissue sections ( $4 \mu \mathrm{m}$ thick) were prepared in a cryostat (Leica Inc., Heidelberg, Germany), air-dried, fixed with acetone, and washed with PBS (38). Tissue sections were incubated with an FITC-conjugated primary reagent or with unlabeled murine mAbs. Unlabeled mAbs were detected by application of a double fluorochrome layer consisting of affinityisolated FITC $\mathrm{F}\left(\mathrm{ab}^{\prime}\right)_{2}$ goat anti-mouse IgG followed by affinity-isolated FITC $\mathrm{F}\left(\mathrm{ab}^{\prime}\right)_{2}$ rabbit anti-goat IgG, both of which were absorbed with human and porcine serum before use. Tissue sections were washed with PBS after application of each reagent and mounted with $p$-phenylenediamine/glycerol solution (39). Background immunofluorescence was assessed by omitting the primary antibody.

Determination of Ig and complement levels. Total serum IgG and IgM was determined by nephelometry, using reagents for human Ig. Plasma C4 levels were determined by functional titration. Properdin and factor $B$ levels were measured by radial immunodiffusion (Kent Laboratories, Redmond, WA).

\section{Results}

Xenoreactive antibodies in human gamma globulin. The amount of xenoreactive natural antibodies in the human IgG preparations was measured by ELISA. As Fig. 1 shows, commercial preparations contained xenoreactive IgG, the binding of which reached saturation at concentrations above $2.5 \mathrm{mg}$ / $\mathrm{ml}$. There was no significant lot-to-lot variability in the level of xenoreactive IgG (not shown). The human IgG preparations contained $<0.4 \%$ IgM, very little of which bound to cultured endothelial cells.

Complement activation by Ig. The ability of the xenoreactive antibodies in the IgG preparations to activate complement was investigated by incubating porcine endothelial cells with IgG and then with human complement and measuring the amount of iC $3 \mathrm{~b}$ neoantigen deposited on the endothelial cell surface. As shown in Fig. $1 B$, xenoreactive human IgG initiated only a modest level of complement activation compared to the level observed when a human serum containing xenoreactive IgM was used.

Effect of IgG on binding of xenoreactive IgM and activation of complement. While our prior studies support the hypothesis that IgG prevents complement-mediated injury by preventing the binding of activated complement to antibody-coated targets $(7,8)$, IgG might also hinder the binding of xenoreactive antibodies through idiotype-antiidiotype interactions $(40,41)$ or through blocking. As Fig. 2 shows, addition of human IgG at various concentrations to human serum did not alter binding of the IgM in that serum to porcine endothelial cells but it did significantly decrease deposition of $\mathrm{C} 4$ and $\mathrm{iC} 3 \mathrm{~b}$ in a dosedependent manner.

Effect of $\mathrm{IgG}$ on complement-mediated cytotoxicity and heparan sulfate release. The ability of IgG to inhibit complementmediated injury was explored in a model in which complement activation depends on the classical pathway $(13,14)$. Endothelial cell monolayers were incubated for $4 \mathrm{~h}$ with $25 \%$ human serum containing varying amounts of human IgG, and specific cytotoxicity was then determined. The addition of IgG to human serum decreased cytotoxicity in a dose-dependent manner by up to $86.9 \pm 5.0 \%$ (Fig. 3 ). Similar results were achieved using four different commercial preparations of gamma globulin (not 


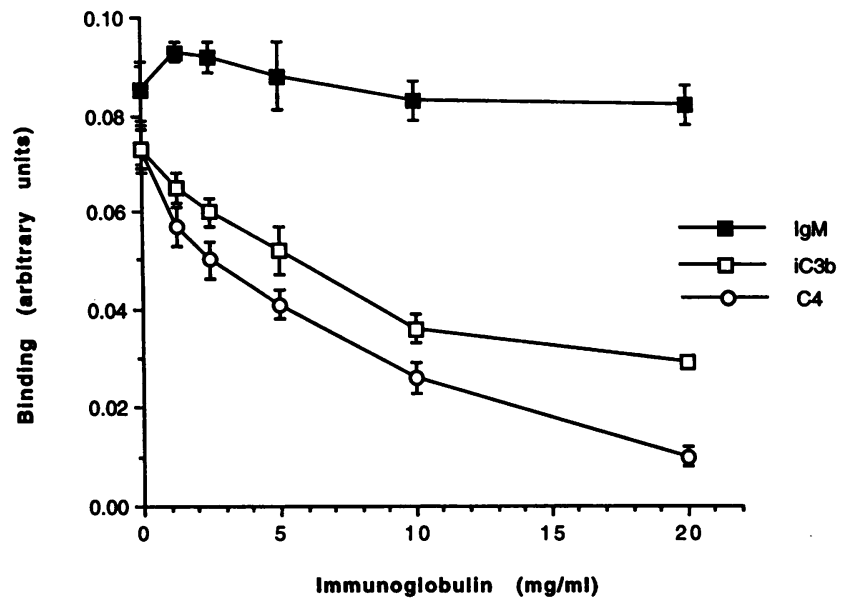

Figure 2. Effect of purified human IgG on binding of xenoreactive IgM to porcine endothelial cells and activation of complement. Porcine aortic endothelial cells were incubated with $25 \%$ human serum to which purified human IgG was added. The binding of IgM and deposition of iC3b and $\mathrm{C} 4$ were then determined by ELISA, and the data expressed as mean absorbance at $405 \mathrm{~nm} \pm$ SEM of duplicate wells. Results are representative of three experiments. Binding expressed as the mean of the slope \pm SEM.

shown). The protective property of IgG was eliminated by heating the immunoglobulin solution to $100^{\circ} \mathrm{C}$ for $15 \mathrm{~min}$ followed by centrifugation (not shown). The protective effect of IgG was not dependent on unique characteristics of the human serum used, as similar results were observed using four different human sera (not shown). The effects of IgG were not a nonspecific effect of the added protein, since addition of BSA to serum had no effect (Fig. 4). Nor was the protective effect due to the carrier solution, since dialyzing the Ig preparation against PBS actually increased protection against complement-mediated cytotoxicity.

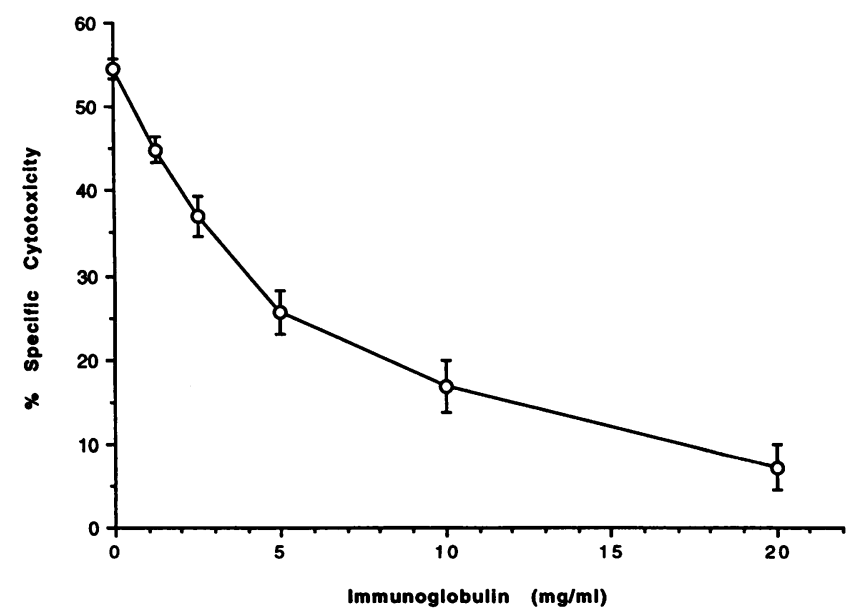

Figure 3. Purified human IgG inhibits complement-mediated cytotoxicity. Porcine aortic endothelial cells were incubated with $25 \%$ human serum to which varying amounts of purified human IgG was added. Cytotoxicity was measured using a ${ }^{51} \mathrm{Cr}$ release assay as described in Methods. Results are expressed as the mean of triplicate wells \pm SEM, and are representative of six experiments.

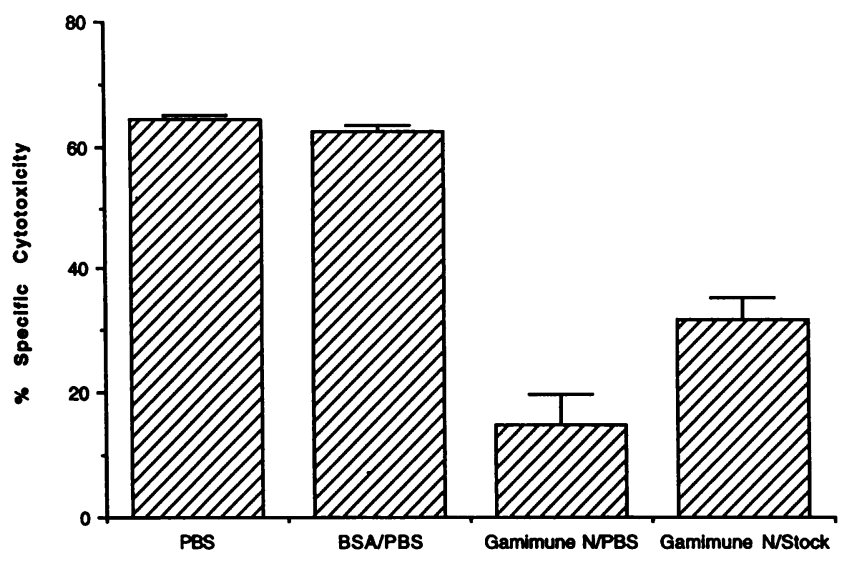

Figure 4. Effect of proteins on cytoprotection mediated by purified human IgG. Porcine aortic endothelial cells were incubated with $25 \%$ human serum for $4 \mathrm{~h}$ in the presence of PBS alone, $10 \mathrm{mg} / \mathrm{ml}$ BSA diluted in PBS, or Gamimune ${ }^{\circledR} \mathrm{N}$ at $10 \mathrm{mg} / \mathrm{ml}$ which was either first dialyzed against PBS or diluted from the stock preparation. The results are expressed as the mean of triplicate wells \pm SEM.

As a measure of noncytotoxic, complement-dependent injury to endothelial cells, the effect of IgG on complementmediated release of heparan sulfate from endothelial cells was evaluated (14). Addition of IgG to human serum decreased heparan sulfate release from porcine endothelial cells in a dosedependent manner by up to $93.2 \pm 2.5 \%$ (not shown).

Prevention of hyperacute rejection in porcine-to-primate cardiac xenografts by IgG. To test whether human IgG would prolong survival of vascularized xenografts, four porcine-tocynomolgus monkey and two porcine-to-baboon cardiac xenografts were performed with administration of IgG in the pretransplant and postoperative period. The results of these experiments are summarized in Table I. In two cynomolgus monkey recipients, hyperacute rejection was prevented; one heart functioned for $8 \mathrm{~d}$ (cyno 1 ), the other for $18 \mathrm{~h}$ when the monkey died suddenly (cyno 3 ). Two xenografts into cynomolgus recipients did not function and appeared to have been rejected hyperacutely (cyno 2 and cyno 4 ).

One pig-to-baboon xenograft survived $10.25 \mathrm{~d}$ (baboon 1 ). In an attempt to further extend xenograft survival, xenoreactive antibodies were depleted by perfusing the blood of a second baboon (baboon 2) through two pig kidneys and then IgG was administered. A porcine cardiac xenograft in this baboon survived $7.5 \mathrm{~d}$. Analysis of the titers of xenoreactive natural antibodies however revealed that the kidney perfusions had not fully depleted xenoreactive IgM, the level of which was comparable to that of baboon 1 (not shown). In baboon 2, there was no significant change in $\mathrm{C} 4$, properdin, or factor B levels after the perfusions.

Histology and immunopathology of cardiac xenografts. The histology of cardiac xenografts protected by purified IgG from hyperacute rejection revealed a few focal hemorrhages but none of the extensive tissue damage, hemorrhage, and thrombosis characteristic of hyperacute rejection. Biopsies on subsequent days revealed vascular lesions and thrombosis typical of acute vascular xenograft rejection, a condition observed when xenograft survival is prolonged by depletion of complement (42).

Immunopathology of xenografts in the animals treated with 
Table I. Effect of Gamma Globulin on Cardiac Xenograft Survival

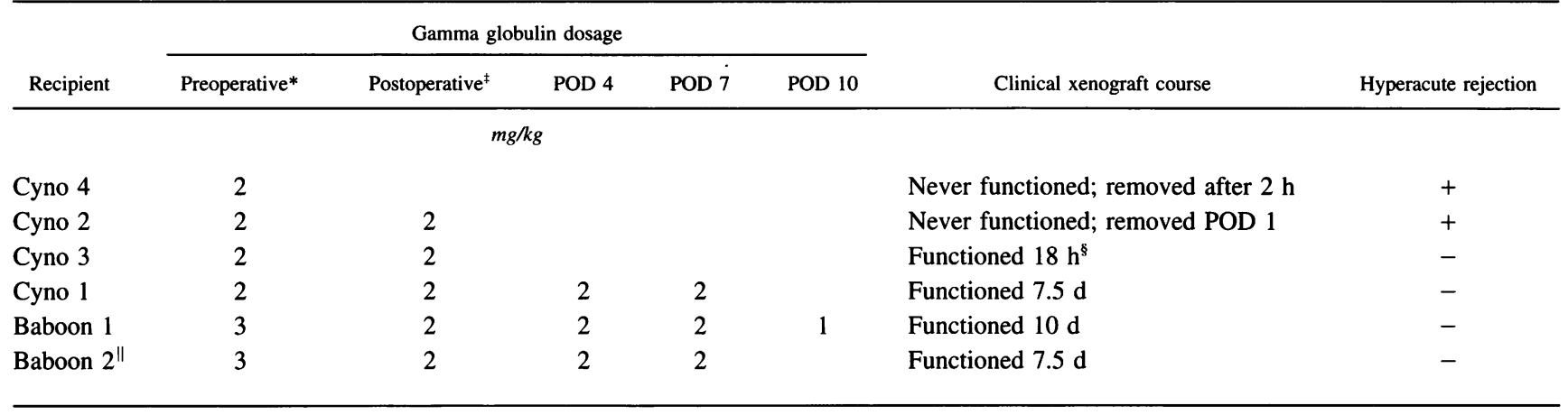

* Preoperative IgG administered $2-16 \mathrm{~h}$ before transplantation. ${ }^{\ddagger}$ Posteroperative IgG administered $6-18 \mathrm{~h}$ after transplantation. ${ }^{\S} \mathrm{Graft}$ was functioning at $18 \mathrm{~h}$ when animals died suddenly. "Baboon 2 was treated with two sequential pig kidney perfusions before administration of IgG and cardiac xenotransplantation as detailed in the text. POD, postoperative day.

IgG demonstrated diffuse staining for IgM and Clq along the endothelium of both large and small blood vessels (Fig. 5). IgG was also present along the endothelium and in extravascular compartments (not shown). Despite the deposition of IgM, IgG, and Clq, the tissues from hearts in which hyperacute rejection did not occur had very little or no dectable $\mathrm{C} 4$, factor $\mathrm{B}$, properdin, C3, C5b, and membrane attack complex (Fig. 5).

The basis for the hyperacute rejection of two xenografts in cynomolgus monkeys treated with human IgG was examined. There was no difference in the titers of xenoreactive antibodies or in graft preservation time between the monkeys in which hyperacute rejection occurred and the monkeys and baboons in which it was prevented. Levels of IgG, C4, properdin, and factor B in serum before transplantation were similar in both groups. The hyperacutely rejected xenografts had prominent deposits of properdin, C3, and membrane attack complex (Fig. 6), but very little or no $\mathrm{C} 4$ (as shown in Fig. 5). Furthermore, the levels of factor $B$ and properdin in the serum of these animals decreased very rapidly after perfusion of the grafts. These results suggested that complement had been activated via the alternative pathway, and these results are consistent with the possibility that Ig may not regulate this pathway to the same content as the classical pathway.

Effect of IgG and xenotransplantation on serum complement activity. Administration of IgG before transplantation resulted in a $16-54 \%$ decrease in $\mathrm{C} 4$ titers. After xenotransplantation, the $C 4$ titer fell rapidly, usually reaching a nadir 30-60 min after transplantation (Fig. 7). This decrease in $\mathrm{C} 4$ was of a magnitude similar to that observed in unmanipulated cynomolgus monkeys after porcine cardiac xenotransplantation (32). The rapid consumption of $\mathrm{C} 4$ after xenotransplantation suggests that the administration of Ig did not prevent the activation of the classical complement pathway but diverted the active complexes away from the graft.

Effect of administration of $\mathrm{IgG}$ and xenotransplantation on xenoreactive IgM and total Ig levels. Consistent with the results of in vitro studies, administration of IgG did not alter substantially the levels of xenoreactive IgM (Fig. 8). As expected, levels of xenoreactive IgM decreased after reperfusion of the grafts, reaching a nadir $1 / 2-24 \mathrm{~h}$ after transplantation. The level of xenoreactive IgM in xenograft recipients began to increase between 1 and $4 \mathrm{~d}$ after transplantation and by posttransplant day 7 had increased appreciably, although the levels remained lower than the pretransplantation values as long as the xenograft continued to function.

After administration of IgG, the concentration of IgG in serum was $40-60 \mathrm{mg} / \mathrm{ml}$ and then decreased to the range of $20-40 \mathrm{mg} / \mathrm{ml}$ (Fig. 9). IgM levels were decreased minimally $24 \mathrm{~h}$ after transplantation but then returned toward baseline levels. These results suggest that administration of IgG did not significantly decrease the synthesis of Ig. In the three cases (cyno 1 and both baboons), total IgM levels fell between 30 min and $24 \mathrm{~h}$ after transplantation, but by the fourth postoperative day, total IgM generally equaled or exceeded the pretransplant level. After rejection and removal of the xenograft, xenoreactive IgM levels rose to levels equal or greater to those observed before xenotransplantation. The titration curves then assumed a different shape, consistent with an alteration in the binding properties of xenoreactive IgM (not shown). Based on these results, it appears that administration of $\mathrm{IgG}$ did not significantly decrease the synthesis of Ig.

\section{Discussion}

Human IgG has been used as a therapeutic agent in the treatment of such autoimmune diseases as idiopathic thrombocytopenic purpura, Kawasaki disease, and myasthena gravis. The therapeutic effects of IgG have been attributed to various mechanisms including the blocking of Fc receptors and antiidiotype inhibition of pathogenic Igs $(40,41)$. Ig may also regulate the complement cascade by preventing the binding of activated complement to antibody-coated targets $(7,8)$. Here we report that IgG administered to a xenograft recipient prevents hyperacute rejection, and we present evidence that it is through the regulation of complement that rejection is averted. The studies reported here are the first in higher primates to demonstrate this mechanism.

Our investigations used a severe model in which the binding of xenoreactive natural antibodies, predominately IgM, to the graft endothelium activates complement via the classical pathway $(11,13,18)$. Complement activation in this model causes a dramatic loss of endothelial integrity and thrombosis leading rapidly to loss of graft function and destruction of organ. The mechanism by which IgG protects against complement-medi- 


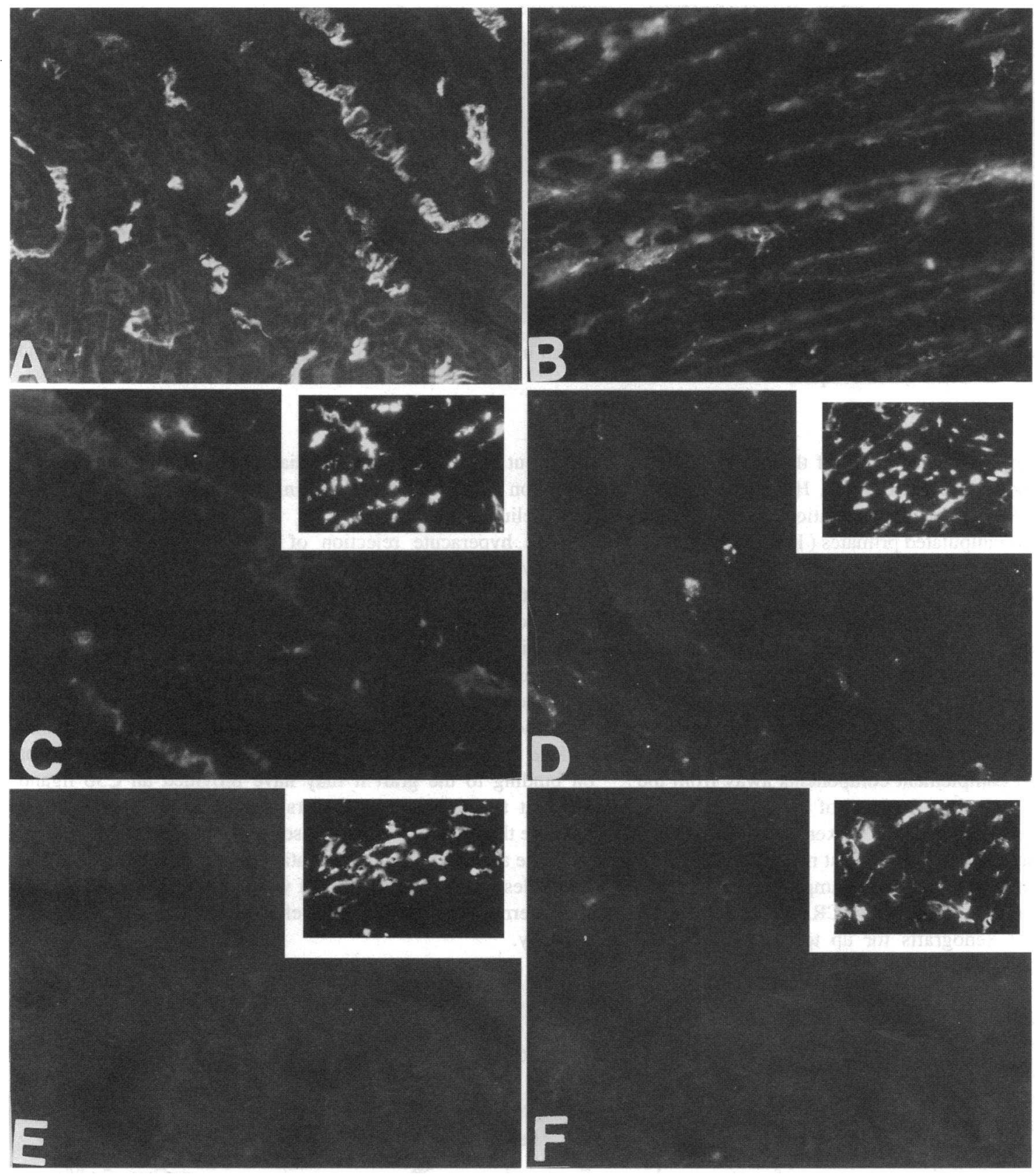

Figure 5. Immunopathology of porcine cardiac xenografts in cynomolgus monkeys treated with purified human IgG. Porcine hearts were transplanted heterotopically into cynomolgus monkeys which had been given $2 \mathrm{~g} / \mathrm{kg}$ human IgG intravenously. Tissue samples obtained by biopsy $24 \mathrm{~h}$ after transplantation are shown. Tissue samples were snap frozen in precooled isopentane, sectioned in a cryostat, fixed with acetone, and stained as follows: $(A) \mathrm{IgM} ;(B) \mathrm{Clq} ;(C) \mathrm{C} 4 ;(D) \mathrm{C} 3 ;(E)$ C5b neoantigen; $(F)$ membrane attack complex neoantigen. In $C-F$, the immunopathology of pig-to-primate cardiac xenografts undergoing hyperacute rejection is shown as an inset for comparison.

ated injury in this model appears to involve prevention of complement deposition rather than inhibition of IgM binding. This mechanism differs from the mechanism proposed by Glotz and associates for the beneficial effects of gamma globulin on the outcome of allografts in presensitized subjects (43). In the allograft recipients, IgG was thought to decrease circulating HLA-specific alloantibodies by idiotype interaction (43). Our results suggest that the complement regulatory effects of gamma globulin might confer additional protection in this setting.
IgG may inhibit complement deposition through one or more of several mechanisms. First, any aggregates present in the IgG preparations might cause the consumption of complement. This mechanism is unlikely to account for our observations because the preparations of gamma globulin used are $>98 \%$ IgG and based on sucrose density gradient ultracentrifugation and gel filtration they are free of aggregates. Nor do the IgG preparations consume complement when administered to humans (7). However, the human IgG might well have formed 

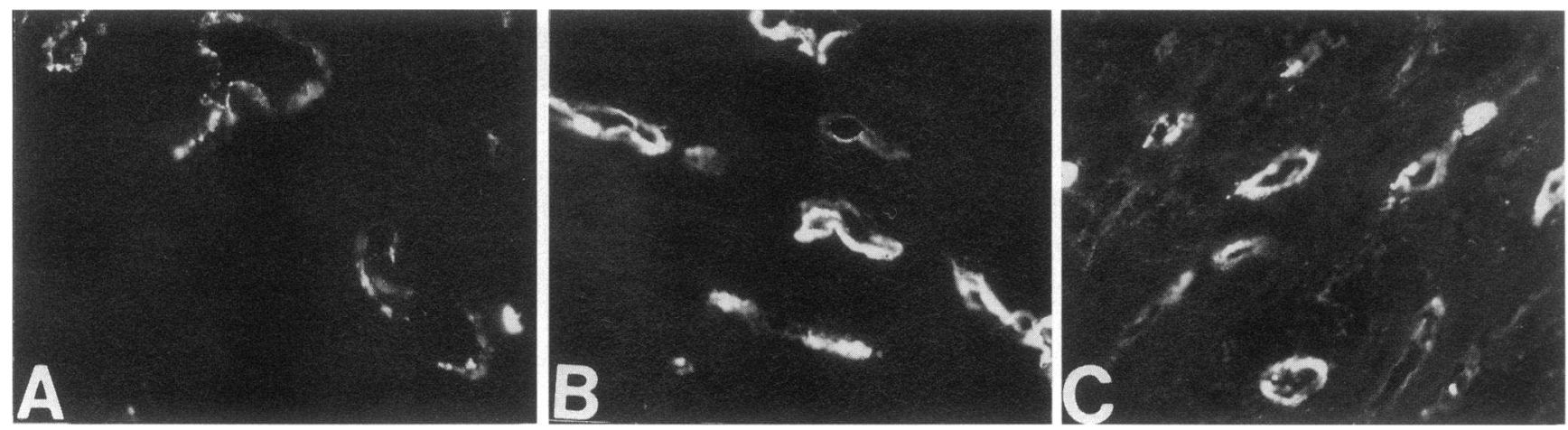

Figure 6. Immunopathology of hyperacute rejection of a porcine cardiac xenograft in a cynomolgus monkey treated with purified human IgG. $(A)$ properdin; $(B) \mathrm{C} 5 \mathrm{~b} ;(C)$ membrane attack complex.

small amounts of complexes with the Ig of the nonhuman primates leading to a modest decrease in $\mathrm{C} 4$. However, the very rapid decline in $\mathrm{C} 4$ levels after transplantation consistent with our observations in unmanipulated primates (13) and deposition of $\mathrm{Clq}$ in the xenografts indicated that the classical pathway of the nonhuman primates was not significantly depleted before transplantation. Second, the presence in gamma globulin of small amounts of soluble HLA antigen might have interfered with antibody binding. This explanation is unlikely as the natural antibodies of baboons are not directed against HLA (44, 45 ). Third and most consistant with our findings is the concept that IgG prevented complement deposition in the xenografts by diversion of activated complement components away from the graft endothelium, at or before the level of $\mathrm{C} 4$.

To our knowledge, the extension of xenograft survival up to $10 \mathrm{~d}$ by administration of $\mathrm{IgG}$ is the best result obtained with a single anticomplement agent. For example, under optimal conditions cobra venom factor (46) or SCR1 (32) prolong the survival of discordant xenografts for up to $5 \mathrm{~d}$. While it is possible that gamma globulin has superior effects against complement, the greater prolongation of xenograft survival in our experiments may well reflect other therapeutic properties of IgG. Another advantage of IgG over other complement inhibitors may be that IgG selectively inhibits the classical pathway allowing the alternative pathway to function in host defense.

In the xenografts surviving more than $7 \mathrm{~d}$, graft failure was associated with prominent evidence of thrombosis and patchy neutrophil infiltration, suggesting occurrence of acute vascular xenograft rejection (42). This type of rejection is poorly under-

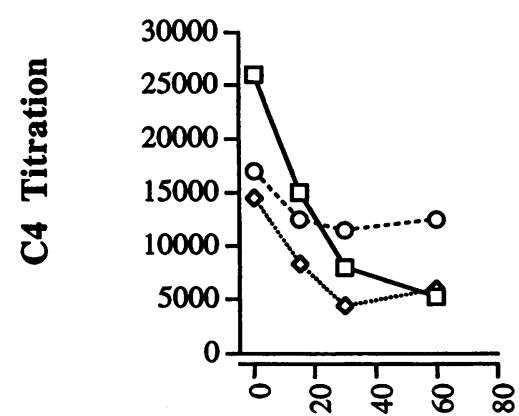

Time in Minutes
Figure 7. Complement C4 levels in xenograft recipients. Complement levels were measured by functional titration. stood but may involve endothelial cell activation resulting in alteration in the coagulant and inflammatory properties of the endothelium $(17,42,47)$.

The hyperacute rejection of two porcine-to-cynomolgus monkey grafts due to activation of the alternative pathway complement is in contrast to the preponderance of our experience in pig-to-primate xenograft models $(11,46)$ and to our experience with perfusion of porcine organs by humans (48). The mechanism of alternative pathway activation in these cases is not understood but several possibilities are worth consideration. First, the human IgG may have rendered the porcine endothelial surface capable of activating the alternative pathway $(3,49)$ or on binding to the graft it may have provided an $\mathrm{C} 3 \mathrm{~b}$ ligand resistant to inhibition by factors $H$ and $I$ (5). Second, it is possible that components expressed by some pigs but not others facilitate activation of the alternative pathway of primates (32). Regardless of the mechanism, it would seem that IgG controls the alternative pathway less effectively than the classical pathway.

The studies reported here support earlier suggestions that

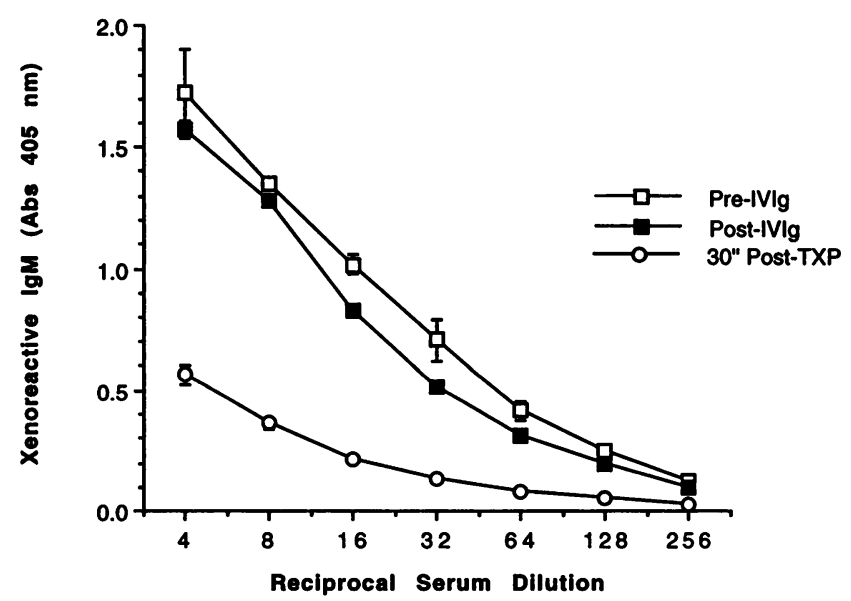

Figure 8. Effect of purified human IgG on the levels of xenoreactive IgM in a xenograft recipient. Xenoreactive IgM was measured in the serum of a cynomolgus monkey prior to and at various times after administration of purified human IgG. Results are expressed as the mean absorbance $(A b s)$ at $405 \mathrm{~nm}$ of duplicate wells \pm SEM. IVIg, intravenous Ig. 


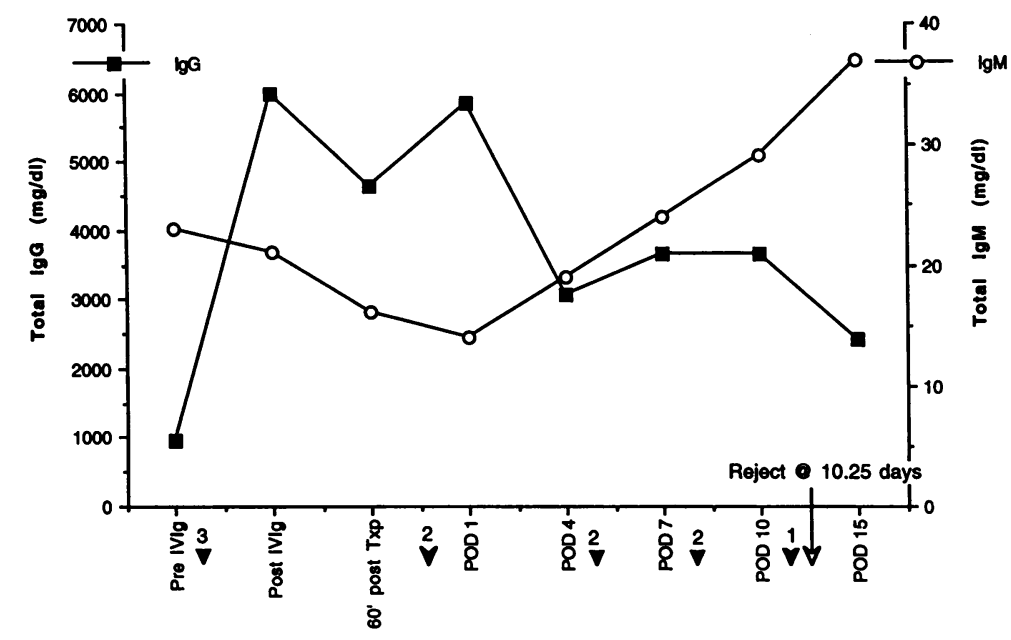

Figure 9. Effect of purified human IgG on total IgG and IgM in a primate recipient of a porcine cardiac xenograft. Total serum IgG and IgM levels were measured by nephelometry before and after administration of purified human IgG. IVIg, intravenous Ig; $P O D$, postoperative day.
IgG is not important in the pathogenesis of hyperacute xenograft rejection in porcine-to-primate xenotransplantation $(11,13)$. Since the IgG preparations used consist almost entirely of functionally active IgG, its administration should enhance whatever pathogenetic mechanisms are initiated by that isotype of Ig. Yet, both in vitro and in vivo, purified IgG protected against complement-mediated injury and showed no evidence of provoking other detrimental changes.

\section{Acknowledgments}

The authors are indebted to Drs. Kenneth McCurry, Cris Alvarado, Adrian Cotterell, and Ravi Chari for their assistance with the in vivo experiments, and Drs. Bill Parker and Vojislav Miletic for assisting with in vitro studies. We also thank Elise Cash, Garren Hester, and Christian Patte for expert technical assistance.

This work was supported by grants from the National Institutes of Health (HL-50985 and HL-52297) and from Nextran, Princeton, NJ.

\section{References}

1. Cooper, N. R. 1985. The classical complement pathway: activation and regulation of the first complement component. Adv. Immunol. 37:151-216.

2. Sim, R. B., and K. B. M. Reid. 1991. C1: molecular interactions with activating systems. Immunol. Today. 12:307-311.

3. Edwards, M. S., A. Nicholson-Weller, C. J. Baker, and D. L., Kasper 1980. The role of specific antibody in alternative complement pathway-mediated opsonophagocytosis of type III, group B streptococcus. J. Exp. Med. 151:12751287.

4. Ratnoff, W. D., D. T. Fearon, and K. F. Austen. 1983. The role of antibody in the activation of the alternative complement pathway. Springer Semin. Immunopathol. 6:361-371.

5. Fries, L. F T. A Gaither, C. H. Hammer, and M. M. Frank. 1984. C3b covalently bound to IgG demonstrates a reduced rate of inactivation by factors $\mathrm{H}$ and I. J. Exp. Med. 160:1640-1655.

6. Joiner, K. A., L. F. Fries, M. A. Schmetz, and M. M. Frank. 1985. IgG bearing covalently bound $\mathrm{C} 3 \mathrm{~b}$ has enhanced bactericidal activity for Escherichia coli 0111. J. Exp. Med. 162:877-889.

7. Basta, M., P. Kirshbom, M. M. Frank, and L. F. Fries. 1989. Mechanism of therapeutic effect on high-dose intravenous immunoglobulin: attenuation of acute, complement-dependent immune damage in a guinea pig model. J. Clin. Invest. 84:1974-1981.

8. Frank, M. M., M. Basta, and L. F. Fries. 1992. The effects of intravenous immune globulin on complement-dependent immune damage of cells and tissues. Clin. Immunol. Immunopathol. 62:S82-S86.

9. Alexandre, G. P. J., P. Gianello, D. Latinne, M. Carlier, A. Dewaele, L. Van Obbergh, M. Moriau, E. Marbaix, J. L. Lambotte, L. Lambotte, and J. P. Squifflet. 1989. Plasmapheresis and splenectomy in experimental renal xenotrans- plantation. In Xenograft 25. M.A. Hardy, editor. Elsevier Science Publishers, New York. 259-266.

10. Cooper, D. K. C., P. A. Human, G. Lexer, A. G. Rose, J. Rees, M. Keraan, and E. Du Toit. 1988. Effects of cyclosporine and antibody adsorption on pig cardiac xenograft survival in the baboon. J. Heart Transplant 7:238-246.

11. Platt, J. L., R. J. Fischel, A. J. Matas, S. A. Reif, R. M. Bolman, and F. H Bach. 1991. Immunopathology of hyperacute xenograft rejection in a swine-toprimate model. Transplantation (Baltimore). 52:214-220.

12. Fischel, R. J., A. J. Matas, J. L. Platt, E. Perry, H. Noreen, S. J. Shumway, and R. M. Bolman. 1992. Cardiac xenografting in the pig to rhesus model: manipulation of anti-endothelial antibody prolongs survival. J. Heart Lung Transplant. 11:965-974.

13. Dalmasso, A. P., G. M. Vercellotti, R. J. Fischel, R. M. Bolman, F. H. Bach, and J. L. Platt. 1992. Mechanism of complement activation in the hyperacute rejection of porcine organs transplanted into primate recipients. Am. J. Pathol. 140:1157-1166.

14. Platt, J. L., G. M. Vercellotti, B. J. Lindman, T. R. Oegema Jr., F. H. Bach, and A. P. Dalmasso. 1990. Release of heparan sulfate from endothelial cells: implications for pathogenesis of hyperacute rejection. J. Exp. Med. 171:1363-1368.

15. Saadi, S., and J. L. Platt. 1995. Transient perturbation of endothelial integrity induced by antibodies and complement. J. Exp. Med. 181:21-31.

16. Platt, J. L., G. M. Vercellotti, A. P. Dalmasso, A. J. Matas, R. M. Bolman, J. S. Najarian, and F. H. Bach. 1990. Transplantation of discordant xenografts: a review of progress. Immunol. Today 11:450-456.

17. Platt, J. L., S. Saadi, and N. S. Ihrcke. 1995. Pathophysiology of xenograft rejection. In Principles of Immunomodulatory Drug Development in Transplantation and Autoimmunity. R. Lieberman and R. Morris, editors. Raven Press, Ltd., New York. In press.

18. Platt, J. L. 1995. Hyperacute Xenograft Rejection. R. G. Landes Co., Austin, T.X.

19. Galili, U., E. A. Rachmilewitz, A. Peleg, and I. Flechner. 1984. A unique natural human IgG antibody with anti- $\alpha$-galactosyl specificity. J. Exp. Med. 160:1519-1531.

20. Galili, U., B. A. Macher, J. Buehler, and S. B. Shohet. 1985. Human natural anti- $\alpha$-galactosyl IgG: the specific recognition of $\alpha(1-3)$-linked glactose residues. J. Exp. Med. 162:573-582.

21. Galili, U., M. R. Clark, S. B. Shohet, J. Buehler, and B. A. Macher. 1987. Evolutionary relationship between the natural anti-Gal antibody and the Gal a13Gal epitope in primates. Proc. Natl. Acad. Sci. USA. 84:1369-1373.

22. Collins, B. H., W. R. Parker, and J. L. Platt. 1994. Characterization of porcine endothelial cell determinants recognized by human natural antibodies. Xenotransplantation. 1:36-46.

23. Parker, W. R., D. Bruno, Z. E. Holzknecht, and J. L. Platt. 1994. Xenoreactive natural antibodies: isolation and initial characterization. J. Immunol. 153:3791-3803.

24. Holzknecht, Z. E., and J. L. Platt. 1995. Identification of porcine endothelial cell membrane antigens recognized by human xenoreactive antibodies. $J$. Immunol. 154:4565-4575.

25. Galili, U. 1993. Interaction of the natural anti-Gal antibody with a-galactosyl epitopes: a major obstacle for xenotransplantation in humans. Immunol. Today. $14: 480-482$.

26. Platt, J. L., B. J. Lindman, R. L. Geller, H. J. Noreen, J. L. Swanson, A. 
P. Dalmasso, and F. H. Bach. 1991. The role of natural antibodies in the activation of xenogenic endothelial cells. Transplantation (Baltimore). 52:1037-1043.

27. Ryan, U. S., and G. Maxwell. 1986. Isolation, culture and subculture of endothelial cells: mechanical methods. J. Tissue Culture Methods. 10:3-5.

28. Falk, R. J., A. P. Dalmasso, Y. Kim, C. H. Tsai, J. I. Scheinman, H Gewurz, and A. F. Michael. 1983. Neoantigen of the polymerized ninth component of complement. Characterization of a monoclonal antibody and immunohistochemical localization in renal disease. J. Clin. Invest. 72:560-573.

29. Platt, J. L., M. A. Turman, H. J. Noreen, R. J. Fischel, R. M. Bolman and F. H. Bach. 1990. An ELISA assay for xenoreactive natural antibodies. Transplantation (Baltimore). 49:1000-1001.

30. Platt, J. L. A. P. Dalmasso, B. J. Lindman, N. S. Ihrcke, and F. H. Bach. 1991. The role of C5a and antibody in the release of heparan sulfate from endothelial cells. Eur. J. Immunol. 21:2887-2890.

31. Collins, B. H., A. H., Cotterell, K. R. McCurry, O. G. Alvarado, J. C. Magee, W. Parker, and J. L. Platt. 1995. Cardiac xenografts between primate species provide evidence for the a-galactosyl determinant in hyperacute rejection. J. Immunol. 154:5500-5510.

32. Pruitt, S. K., A. D. Kirk, R. R. Bollinger, H. C. Marsh, Jr. B. H. Collins, J. L. Levin, J. R. Mault, J. S. Heinle, S. Ibrahim, A. R. Rudolph, et al. 1994. The effect of soluble complement receptor type 1 on hyperacute rejection of porcine xenografts. Transplantation (Baltimore). 57:363-370.

33. McCurry, K. R., D. L. Kooyman, C. G. Alvarado, A. H. Cotterell, M. J. Martin, J. S. Logan, and J. L. Platt. 1995. Human complement regulatory proteins protect swine-to-primate cardiac xenografts from humoral injury. Nature Medicine. 1:423-427.

34. Michler, R. E., R. P. McManus, C. R. Smith, A. N. Sadeghi, and E. A Rose. 1985. Technique for primate heterotopic cardiac xenotransplantation. $J$. Med. Primatol. 14:357-362.

35. Sadeghi, A. M., R. C. Robbins, C. R. Smith, P. A. Kurlansky, R. E. Michler, K. Reemtsma, and E. A. Rose. 1987. Cardiac xenotransplantation in primates. J. Thorac. Cardiovasc. Surg. 93:809-814.

36. Sadeghi, A. M., R. C. Robbins, C. R. Smith, R. A. Kurlensky, R. E. Michler, K. Reemtsma, and E. A. Rose. 1987. Cardiac xenograft survival in baboons treated with cyclosporine in combination with conventional immunosuppression. Transplant. Proc. 19:1149-1152.

37. Alvarado, C. G., A. H. Cotterell, K. R. McCurry, B. H. Collins, J. C. Magee, J. Berthold, J. S. Logan, and J. L. Platt. 1995. Variation in the level of xenoantigen expression in porcine organs. Transplantation (Baltimore). 59:1589_ 1596.

38. Platt, J. L., B. W. Grant, A. A. Eddy, and A. F. Michael. 1983. Immune cell populations in cutaneous delayed-type hypersensitivity. J. Exp. Med. 158:1227-1242.

39. Platt, J. L., and A. F. Michael. 1983. Retardation of fading and enhancement of intensity of immunofluorescence by $p$-phenylenediamine. J. Histochem Cytochem. 31:840-842.

40. Dwyer, J. M. 1994. Manipulating the immune system with immune globulin. N. Engl. J. Med. 326:107-116.

41. Ronda N. V. Hurez and M. D. Kazatchkine 1993. Intravenous immunoglobulin therapy of autoimmune and systemic inflammatory diseases. Vox Sang. 64:65-72.

42. Leventhal, J. R., A. J. Matas, L. H. Sun, S. Reif, R. M. Bolman III, A. P. Dalmasso, and J. L. Platt. 1993. The immunopathology of cardiac xenograft rejection in the guinea pig to rat model. Transplantation (Baltimore). 56:1-8.

43. Glotz, D., J. P. Haymann, N. Sansonetti, A. Francois, V. Menoyo-Calonge, J. Bariety, and P. Druet. 1994. Suppression of HLA-specific alloantibodies by high-dose intravenous immunoglobulins (IVIg). Transplantation (Baltimore). 56:335-337.

44. Platt, J. L., B. J. Lindman, H. Chen, S. L. Spitalnik, and F. H. Bach. 1990 Endothelial cell antigens recognized by xenoreactive human natural antibodies. Transplantation (Baltimore). 50:817-822.

45. Satake, M., N. Kawagishi, L. Rydberg, B. E. Samuelsson, A. Tibell, C. Groth, and E. Moller. 1994. Limited specificity of xenoantibodies in diabetic patients transplanted with fetal porcine islet cell clusters. Main antibody reactivity against a-linked galactose-containing epitopes. Xenotransplantation. 1:89-101.

46. Leventhal, J. R., A. P. Dalmasso, J. W. Cromwell, J. L. Platt, C. J. Manivel, R. M. Bolman, and A. J. Matas. 1993. Prolongation of cardiac xenograft survival by depletion of complement. Transplantation (Baltimore). 55:857-866.

47. Magee, J. C., and J. L. Platt. 1994. Xenograft rejection: molecular mechanisms and therapeutic implications. Therapeutic Immunol. 1:45-58.

48. Collins, B. H., R. S. Chari, J. C. Magee, R. C. Harland, B. J. Lindman J. S. Logan, R. R. Bollinger, W. C. Meyers, and J. L. Platt. 1994. Mechanisms of injury in porcine livers perfused with blood of humans with fulminant hepatic failure. Transplantation (Baltimore). 58:1162-1171.

49. Moore, F. D. Jr., K. F. Austen, and D. T. Fearon. 1982. Antibody restores human alternative complement pathway activation by mouse erythrocytes rendered functionally deficient by pretreatment with pronase. J. Immunol. 128:13021306. 